\begin{tabular}{l|l|l|l}
$\begin{array}{l}\text { Case Reports in } \\
\text { Ophthalmology }\end{array}$ & $\begin{array}{l}\text { Case Rep 0phthalmol 2010;1:14-19 } \\
\text { Dol: } 10.1159 / 000315489\end{array}$ & Published online: June 11, 2010 & $\begin{array}{l}\text { ○ 2010 S. Karger AG, Basel } \\
\text { ISSN 1663-2699 } \\
\text { www.karger.com/cop }\end{array}$ \\
\hline
\end{tabular}

\title{
Cystoid Macular Edema: Possible Complication of Infliximab Therapy in Behçet's Disease
}

\author{
Junko Ikewaki ${ }^{a}$ Hirofumi Kono ${ }^{a}$ Kei Shinodaa,b \\ Toshiaki Kubota ${ }^{a}$ Kazuo Nakatsuka ${ }^{a}$ \\ ${ }^{\text {aDDepartment }}$ of Ophthalmology, Oita University Faculty of Medicine, Oita, and \\ ${ }^{b}$ Department of Ophthalmology, Teikyo University School of Medicine, Tokyo, \\ Japan
}

\section{Key Words}

Cystoid macular edema - Infliximab - Behçet's disease

\begin{abstract}
Aim: Infliximab, an anti-tumor necrosis factor (TNF)-a monoclonal antibody, has been reported to be effective in refractory uveoretinitis in Behçet's disease. Because it has been used clinically for a short time, information on its adverse effects is limited. We report a patient who developed cystoid macular edema (CME) following infliximab use for uveoretinitis associated with Behçet's disease.

Case Report: A 27-year-old man had refractory uveoretinitis and neuro-Behçet's disease, and intravenous infliximab was administered.

Results: One day after infliximab infusion, the patient complained of a decrease in the vision in his left eye. The visual acuity had decreased from 1.2 to 0.5 . Daily optical coherence tomographic evaluations showed a progressive worsening of the $C M E$, and fluorescein angiography showed a typical staining with a cystic pattern. Two weeks later, the height of CME appeared to reach a maximum level and thereafter gradually resolved in spite of the continuation of infliximab administration. The visual acuity improved while the patient was treated with repeated subtenon injections of steroids in addition to continuation of infliximab and finally increased from 0.15 to 1.2 .

Conclusions: Although the mechanism of CME is not known, clinicians should be aware that infliximab therapy might cause a development and worsening of CME. Thus, it is crucial to rule out preexisting abnormalities in the macula prior to commencing infliximab infusion.
\end{abstract}




\begin{tabular}{l|l|l|l}
$\begin{array}{l}\text { Case Reports in } \\
\text { Ophthalmology }\end{array}$ & $\begin{array}{l}\text { Case Rep 0phthalmol 2010;1:14-19 } \\
\text { Dol: 10.1159/000315489 }\end{array}$ & Published online: June 11, 2010 & $\begin{array}{l}\text { ○ 2010 S. Karger AG, Basel } \\
\text { ISSN 1663-2699 } \\
\text { www.karger.com/cop }\end{array}$ \\
\hline
\end{tabular}

\section{Introduction}

Infliximab, a monoclonal IgG1 chimeric antibody against soluble and membranebound anti-tumor necrosis factor (TNF)- $\alpha$, is widely used to treat rheumatoid arthritis and Crohn's disease. Its use has been extended to refractory uveoretinitis in Behçet's disease since 2007 in Japan. The clinical findings showed that infliximab decreased the number of ocular attacks, and the findings suggested that it has a beneficial effect on chronic cystoid macular edema (CME). We report an unusual case of a 27-year-old man who developed CME after receiving infliximab for Behçet's disease.

\section{Case Report}

A 27-year-old man was referred to our clinic with recurrent uveitis, aphthous ulcers of the oral mucosa, and genital ulcers in September 2005. His best-corrected visual acuity (BCVA) was 1.0 OD and 1.2 OS. We diagnosed the patient with Behçet's disease and treated him with colchicines and steroid eye drops. A subtenon injection of triamcinolone acetonide was given after each ocular attack. However, the frequency of ocular attacks increased with an increase in the density of bilateral cataracts especially in the right eye. The right eye developed uveoretinitis and refractory CME, and the visual acuity progressively decreased. No macular lesion was found in the left eye, and the visual acuity remained at 1.2 .

In October 2007, the patient was admitted to our hospital with headaches, vertigo, and diplopia, and was diagnosed with neuro-Behçet's disease with a brain lesion. He was examined by a neurologist, and it was jointly decided to treat the refractory uveoretinitis and neuro-Behcet's disease with infliximab. His BCVA was $0.08 \mathrm{OD}$ and $1.2 \mathrm{OS}$ one day before the infusion of infliximab. His right eye had moderate iritis, progressive cataracts, retinal vasculitis, macular edema, and optic disc pallor. His left eye had slight iritis and cataract, but showed no abnormality by ophthalmoscopy and optical coherence tomography (OCT; fig. 1). Fluorescein angiography (FA) showed retinal vasculitis in both eyes (fig. 2 ).

One day after the infusion of infliximab, he complained of blurred vision in his left eye. The BCVA was reduced to $0.08 \mathrm{OD}$ and 0.5 OS. Fundus scanning by OCT showed a CME in the left eye (fig. 1). On the next day, the BCVA in the left eye decreased to 0.15 , and the CME detected by OCT progressively worsened (fig. 1). FA 4 days after the first infusion of infliximab showed an increase in the severity of the CME (fig. 2), but the visual acuity improved to 0.6 OS in spite of the exacerbation of the CME. Two weeks after the first infusion of infliximab, a second infusion of the drug was done with a daily subtenon injection of $2 \mathrm{mg}$ of dexamethasone sodium phosphate in the left eye for 1 week to prevent the worsening of the CME. There was no worsening of the CME after the second infusion of infliximab. One month after the first infusion of infliximab, the left BCVA improved to 1.2, and with no additional treatment, the CME was gradually reduced and completely resolved 3 months later. The CME in the left eye has not recurred since then. The CME in the right eye did not respond to the multiple subtenon injections of triamcinolone acetonide, but it appeared to have improved 21 months after the initiation of infliximab therapy.

\section{Discussion}

Evidence has accumulated that infliximab can control refractory uveoretinitis in Behçet's disease [1-3]. In addition, infliximab has been reported to have beneficial effects on CME associated with chronic uveitis in Behçet's disease [4]. Our patient complained of visual disturbances, and OCT showed a development and worsening of a CME after the first administration of infliximab. The CME worsened in the OCT images, but the BCVA gradually improved although the treatment regime was not altered. Thus, we decided to continue the therapy with infliximab. We treated the patient with a daily subtenon injection of dexamethasone sodium phosphate for 1 week after the second administration of infliximab, and a worsening of the CME did not occur. The CME gradually improved 


\begin{tabular}{l|l|l|l}
$\begin{array}{l}\text { Case Reports in } \\
\text { Ophthalmology }\end{array}$ & $\begin{array}{l}\text { Case Rep 0phthalmol 2010;1:14-19 } \\
\text { Dol: 10.1159/000315489 }\end{array}$ & Published online: June 11, 2010 & $\begin{array}{l}\text { ○ 2010 S. Karger AG, Basel } \\
\text { ISSN 1663-2699 } \\
\text { www.karger.com/cop }\end{array}$ \\
\hline
\end{tabular}

even with the continued use of infliximab. The occurrence of CME has not been reported as a side effect of infliximab.

On the other hand, it has been suggested that infliximab might be immunogenic and probably retinotoxic $[5,6]$. Giganti et al. [5] reported that intravitreal infliximab in patients with refractory diabetic macular edema or choroidal neovascularization secondary to age-related macular degeneration was not well tolerated. The adverse events included persistence of CME, worsened appearance on angiography, development of inflammation (vitritis or panuveitis), and decrease of electroretinographically-determined retinal function. They mentioned that the undiminished diffuse edema and downward trend in ERG values seen in their patients partly corresponded with the findings observed in experimental rabbit eyes following relative high-dose intravitreal infliximab injection [6]. It is assumed that the possible mechanism involved in the complication in our patient was induced immune response, which may aggravate the CME. This is an adverse event in a single case and cannot be regarded as a definite adverse effect of the drug for patients with ocular Behçet's disease. However, given the reasonable association of infliximab with $\mathrm{CME}$, it might be crucial to rule out preexisting abnormalities in the macula prior to commencing infliximab infusion.

\section{Acknowledgements}

Support of this study was provided by Research Grants on Sensory and Communicative Disorders from the Ministry of Health, Labour, and Welfare, Japan, and from the Ministry of Education, Culture, Sports, Science and Technology, Japan. 


\begin{tabular}{l|l|l|l}
$\begin{array}{c}\text { Case Reports in } \\
\text { Ophthaimology }\end{array}$ & $\begin{array}{l}\text { Case Rep Ophthalmol 2010;1:14-19 } \\
\text { D0I: 10.1159/000315489 }\end{array}$ & Published online: June 11, 2010 & $\begin{array}{l}\text { O 2010 S. Karger AG, Basel } \\
\text { ISSN 1663-2699 } \\
\text { www.karger.com/cop }\end{array}$ \\
\hline
\end{tabular}

Fig. 1. Optical coherence tomographic images of the left eye before and after the infliximab injection. a No obvious abnormalities are seen in the left macula 1 day before the first infliximab infusion. Visual acuity was 1.2. b One day after the first infliximab infusion, the outer nuclear layer appears to be thicker at the macula suggesting the beginning of macular edema. Visual acuity was 0.5 . $\mathbf{c}$ Two days after the first infliximab infusion, macular edema can be seen. Visual acuity was 0.1 . d Four days after the first infliximab infusion, OCT image showing that the macular edema is worsened and cystoid spaces in the inner nuclear layer can also be seen. This image was obtained on the same day as the fundus photographs of figures $2 \mathrm{c}$ and $\mathrm{d}$. Despite the OCT findings, visual acuity improved to 0.6 . e Fourteen days after the first infliximab infusion, localized serous retinal detachment developed within the still remaining macular edema. Again, contrary to the OCT findings, visual acuity further improved to 0.7. f One month after the first infliximab infusion, the macular edema is resolved and visual acuity improved to 1.2 .
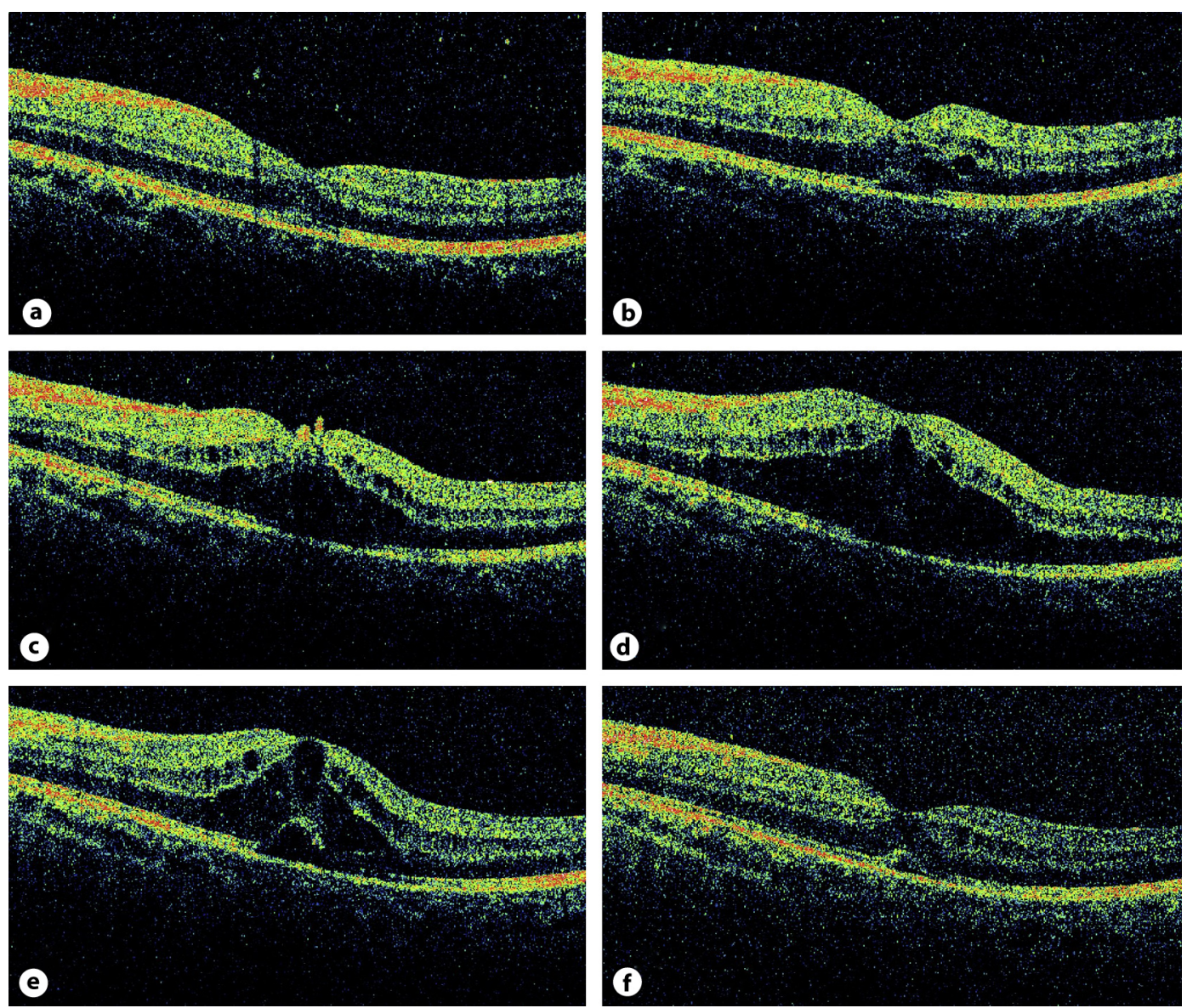


\begin{tabular}{l|l|l|l}
$\begin{array}{l}\text { Case Reports in } \\
\text { Ophthalmology }\end{array}$ & $\begin{array}{l}\text { Case Rep 0phthalmol 2010;1:14-19 } \\
\text { Dol: } 10.1159 / 000315489\end{array}$ & Published online: June 11, 2010 & $\begin{array}{l}\text { ○ 2010 S. Karger AG, Basel } \\
\text { ISSN 1663-2699 } \\
\text { www.karger.com/cop }\end{array}$ \\
\hline
\end{tabular}

Fig. 2. Fundus FA before and after infliximab infusion. Top: FA, performed 1 day before the first infusion of infliximab, showed diffuse dye leakage involving macula of the right eye (a) and slight macular leakage and retinal vasculitis in the left eye (b). Bottom: FA, performed 4 days after the first infusion of infliximab (taken on the same day as that in fig. 1d), shows still active diffuse dye leakage involving the macula in the right eye (c) and extensive dye pooling and staining with a cystic pattern in the macula in the left eye (d).
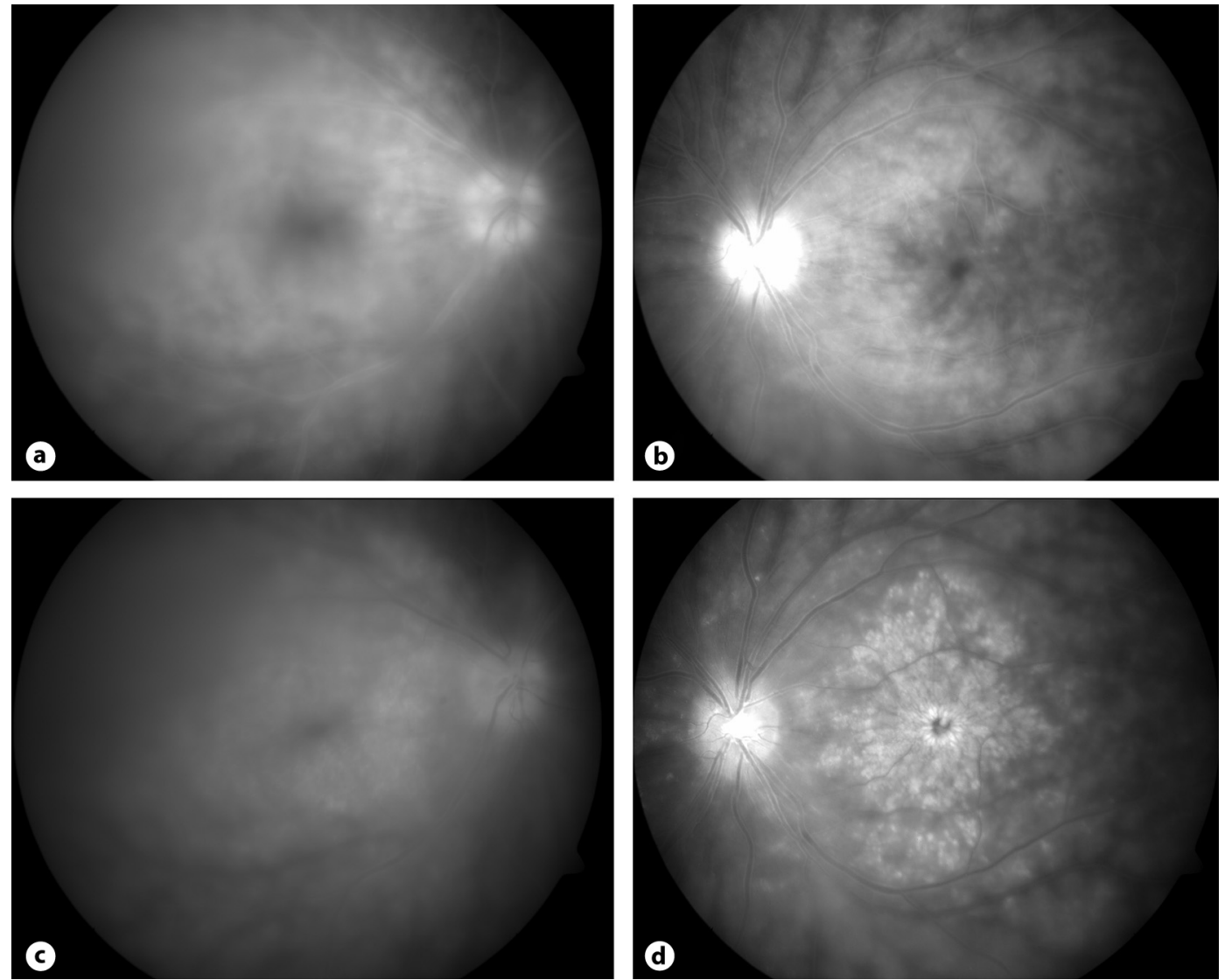


\begin{tabular}{l|l|l|l}
$\begin{array}{l}\text { Case Reports in } \\
\text { Ophthalmology }\end{array}$ & $\begin{array}{l}\text { Case Rep 0phthalmol 2010;1:14-19 } \\
\text { Dol: } 10.1159 / 000315489\end{array}$ & Published online: June 11, 2010 & $\begin{array}{l}\odot \text { 2010 S. Karger AG, Basel } \\
\text { ISSN 1663-2699 } \\
\text { www.karger.com/cop }\end{array}$ \\
\hline
\end{tabular}

\section{References}

1 Tabbara KF, Al-Hemidan AI: Infliximab effects compared to conventional therapy in the management of retinal vasculitis in Behçet disease. Am J Ophthalmol 2008;146:845-850.

2 Yamada Y, Sugita S, Tanaka H, Kamoi K, Kawaguchi T, Mochizuki M: Comparison of infliximab versus cyclosporine during the initial 6-month treatment period in Behçet's disease. Br J Ophthalmol 2010;94:284-288.

-3 Lopez-Gonzalez R, Loza E, Jover JA, Benitez Del Castillo JM, Mendez R, Hernandez-Garcia C, Pato E: Treatment of refractory posterior uveitis with infliximab: a 7-year follow-up study. Scand J Rheumatol 2009;38:58-62.

-4 Markomichelakis NN, Theodossiadis PG, Pantelia E, Papaefthimiou S, Theodossiadis GP, Sfikakis PP: Infliximab for chronic cystoid macular edema associated uveitis. Am J Ophtahalmol 2004;138:648-650.

5 Giganti M, Beer PM, Lemanski N, Hartman C, Schartman J, Falk N: Adverse events after intravitreal infliximab (Remicade). Retina 2010;30:71-80.

-6 Theodossiadis PG, Liarakos VS, Sfikakis PP, Charonis A, Agrogiannis G, Kavantzas N, Vergados IA: Intravitreal administration of the anti-TNF monoclonal antibody infliximab in the rabbit. Graefes Arch Clin Exp Ophthalmol 2009;247:273-281. 